\title{
Little League shoulder: a growth plate injury
}

\author{
Christopher Anton • Daniel J. Podberesky
}

Received: 14 September 2010 / Accepted: 30 September 2010 /Published online: 23 October 2010

(C) Springer-Verlag 2010

A 13-year-old boy, a baseball pitcher, presented with right shoulder pain while throwing. The external oblique image shows widening, irregularity and fragmentation of the proximal humeral physis (Fig. 1). Figure 2 is a comparison radiograph of the asymptomatic left shoulder.

Little League shoulder was first described by Dotter [1] in 1953. This injury is commonly known as proximal humeral epiphysiolysis, a confusing term, because Little League shoulder is likely an overuse or stress injury of the proximal humeral growth plate or the adjacent metaphysis rather than

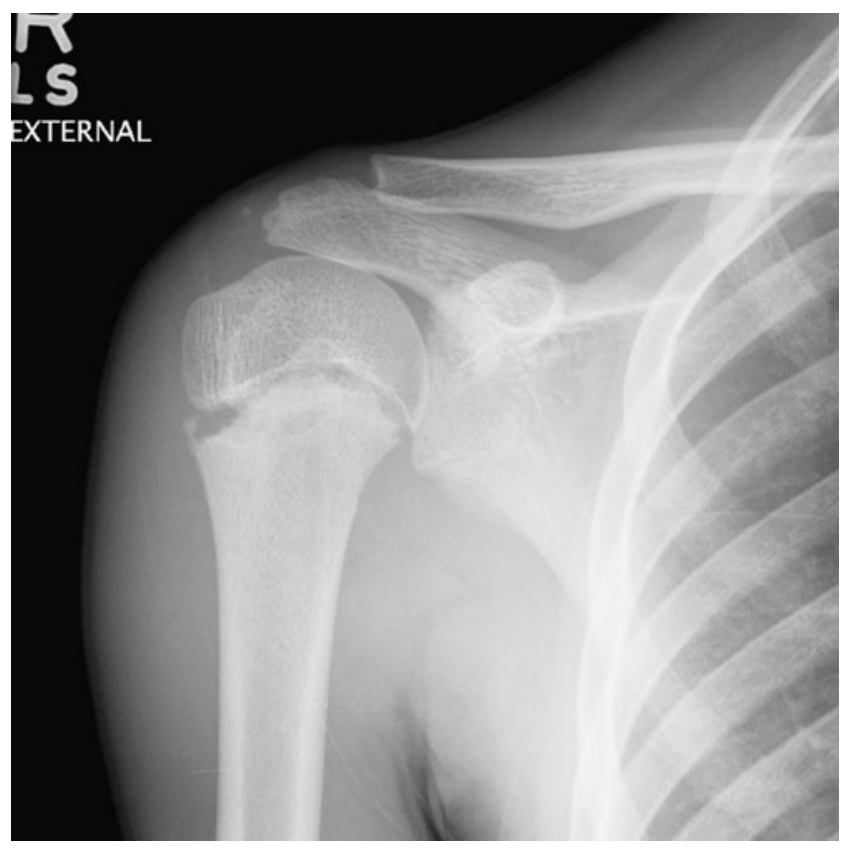

Fig. 1 External oblique right shoulder radiograph

C. Anton $(\bowtie) \cdot$ D. J. Podberesky

Department of Radiology, Cincinnati Children's

Hospital Medical Center,

3333 Burnet Ave.,

Cincinnati, OH 45229-3039, USA

e-mail: christopher.anton@cchmc.org

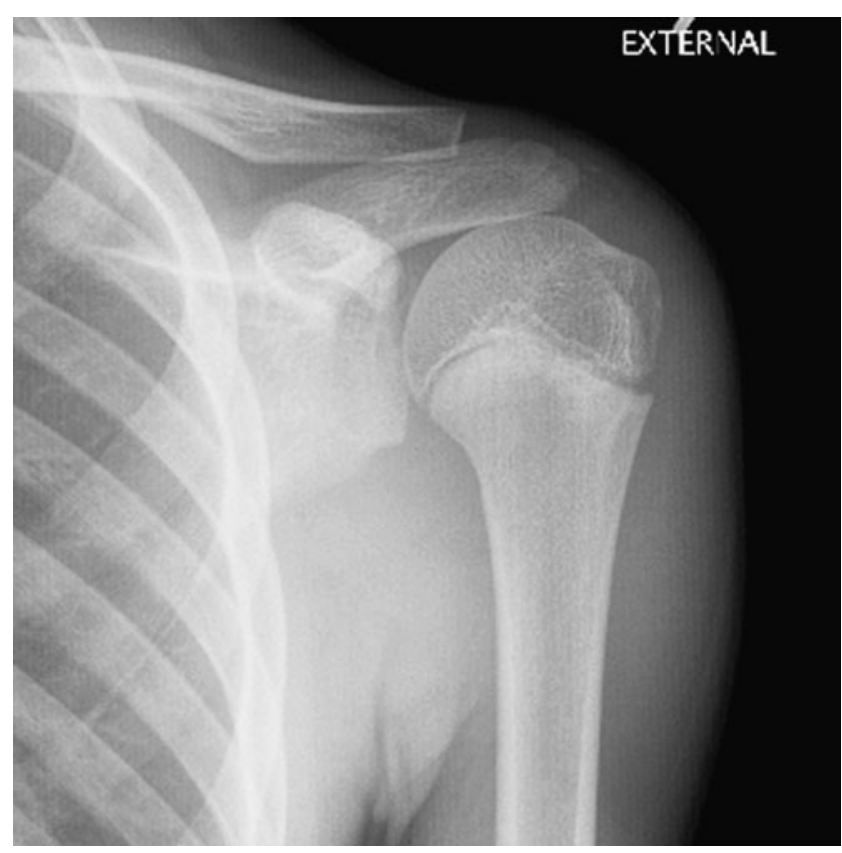

Fig. 2 External oblique left shoulder radiograph

an epiphyseal injury. Little League shoulder is most commonly seen in 13- to 16-year-old boys. The etiology is likely repetitive rotational stress [2]. The physis is particularly prone to injury in this age group because of accelerated growth and the majority of longitudinal humeral growth occurring at the proximal humeral physis. The classic radiographic signs are physeal widening, lateral fragmentation or calcification, sclerosis, demineralization and cystic change [2]. Treatment consists of rest and physical therapy.

\section{References}

1. Dotter WE (1953) Little Leaguer's shoulder. Gutherie Clin Bull 23:68

2. Carson WG Jr, Gasser SI (1998) Little Leaguer's shoulder. A report of 23 cases. Am J Sports Med 26:575-580 